\title{
Modeling trophic interactions to assess the effects of a marine protected area: case study in the NW Mediterranean Sea
}

\author{
Audrey Valls ${ }^{1,3, *}$, Didier Gascuel ${ }^{1}$, Sylvie Guénette ${ }^{1}$, Patrice Francour ${ }^{2}$ \\ ${ }^{1}$ Université Européenne de Bretagne, Pôle halieutique Agrocampus Ouest, UMR 985 Ecologie et Santé des Ecosystèmes, \\ CS 84215, 35042 Rennes cedex, France \\ ${ }^{2}$ Université de Nice Sophia-Antipolis, Faculté des Sciences, EA 4228 ECOMERS, 06108 Nice cedex 2, France \\ ${ }^{3}$ Present address: University of British Columbia, AERL, Fisheries Centre, Vancouver, British Columbia V6T1Z4, Canada
}

\begin{abstract}
The present study describes the food web and evaluates the effects of a marine protected area (MPA), the Port-Cros National Park (NW Mediterranean Sea), on the marine ecosystem inside the reserve and its potential to sustain resources outside the reserve. We built an Ecopath model of the Port-Cros MPA which comprised 41 functional groups and represented an average situation for the period 1998 to 2008. At a high trophic level, fish were dominated by the amberjacks and large dusky grouper groups, 2 abundant top predators playing a central role in the ecosystem in terms of keystone species and trophic cascades. The biomass accumulation rate estimated with Ecopath could reach $10 \% \mathrm{yr}^{-1}$ for large dusky groupers, which is consistent with field observations, suggesting that the MPA succeeded in protecting the species. The total export from the MPA was estimated at a maximum of about 100 tons $\mathrm{yr}^{-1}$, which limits the benefits at a local scale. EcoTroph fishing scenarios showed that the current state of the ecosystem inside the reserve was close to the unexploited state, and that current fishing practices had an insignificant impact. The major effects of the MPA were to protect the high trophic level groups and thus to maintain the functional biodiversity within the reserve. In summary, trophic modeling seems to be a relevant approach to study the effects of MPAs and to improve their management.
\end{abstract}

KEY WORDS: Ecosystem modeling - Reserve effect - Fishing impact - Ecopath - EcoTroph · Keystone species $\cdot$ Biomass export $\cdot$ Port-Cros $\cdot$ Mediterranean Sea

Resale or republication not permitted without written consent of the publisher

\section{INTRODUCTION}

The Mediterranean Sea harbors up to $6.27 \%$ of the world's marine species (depending on the group considered), whereas it is only $0.82 \%$ in surface area and $0.32 \%$ in volume of the world's oceans, and endemism represents more than one quarter of the entire Mediterranean biota (Coll et al. 2010). However, Mediterranean biodiversity is undergoing rapid alteration under combined environmental and anthropogenic impacts, experiencing climate change, heavy demographic, urban and industrial pressure, and also fishing (Coll et al. 2010). In turn, biodiversity loss leads to a decrease in the economic activities dependent on the quality of marine resources, such as fishing or tourism (Sumaila et al. 2000).

Marine protected areas (MPAs) have become a popular tool to reduce human impact on marine ecosystems (Allison et al. 1998), notably in the Mediterranean Sea, where about a hundred of them have already been established (Abdulla et al. 2008). MPAs are expected to allow exploited fish populations to increase in biomass, mean age, and length (Francour et al. 2001, Halpern \& Warner 2002). At the ecosystem level, the effects are different whether the species considered are large predators or small foraging fishes, and depending on changes in ecosystem structure and function induced by reducing fishing 
mortality (Mosquera et al. 2000, Murawski et al. 2005).

The purpose of our study was to assess the potential effects of an MPA on the whole marine food web, using a trophodynamic modeling approach. The Port-Cros National Park (north-western Mediterranean Sea), established in 1963, was considered as a case study. This French National Park comprises a small MPA of $13 \mathrm{~km}^{2}$, with near-shore rocky reef bottoms and economically important biological resources, such as fish and large decapod crustaceans (Francour et al. 2001). Like in most Mediterranean MPAs, a complex zoning of usages is practiced in the Port-Cros MPA (Francour et al. 2001) and only a small portion of the MPA is actually completely closed to all professional fishing activities (about $5 \%$ of the MPA). In the Mediterranean, recent studies have focused on the effects of MPAs using ecosystem models. Libralato et al. (2010) compared the food web structure inside a small protected area to a neighboring exploited area in the northern Adriatic Sea. Albouy et al. (2010) also used an ecosystem model and temporal simulations to evaluate the benefits of the Bonifacio MPA and the potential effects of artisanal and recreational fisheries.

In the present study, we assessed the potential effects of the reserve on the ecosystem by modeling trophic interactions inside the MPA, using a wellknown software and approach - Ecopath with Ecosim (EwE) (Christensen \& Pauly 1992, Christensen \& Walters 2004) - and the EcoTroph plug-in recently added to the EwE family (Gascuel 2005, Gascuel et al. 2011). First, we built an Ecopath model that synthesized the available ecological and fishing data and then analyzed species interactions. This snapshot image of the ecosystem was used as the reference model and modified to test 3 hypotheses on migration and estimate the potential exports that the MPA might produce. Next, using the EcoTroph model based on the Ecopath model, we simulated various hypothetical fishing scenarios and explored the effects of MPA-induced reductions in fishing mortality on the trophic functioning of the ecosystem. These findings were used to provide guidelines to the Port-Cros National Park Authority.

\section{MATERIALS AND METHODS}

\section{Study area}

The Port-Cros National Park's MPA is a small, insular, north-western Mediterranean MPA, located near
Toulon, France $\left(43^{\circ} 00^{\prime} \mathrm{N}, 6^{\circ} 23^{\prime} \mathrm{E}\right)$ (Fig. 1), and was created in 1963. The National Park is an archipelago comprising a main island, the Port-Cros Island, and 3 smaller islands. The MPA is a $600 \mathrm{~m}$ wide belt around the archipelago, for a total area of 1288 ha and a maximum depth of about $50 \mathrm{~m}$. We considered and represented the total volume of the MPA in our modeling approach (up to $600 \mathrm{~m}$ offshore and $50 \mathrm{~m}$ depth).

In Port-Cros, fishing has been permitted with restrictions, owing to social and economic pressures. No-fishing areas (located around ports and diving and swimming areas) represent only about $5 \%$ of the MPA. Outside these restricted areas, specific regulations for professional fishing enshrined in a charter since 1999 limit the size, length, or number of nets, and also the sectors, durations, and periods of fishing. From 1990 to 2004, recreational fishing has been progressively restricted to half of the MPA, as the significant amount of catches taken by recreational fishing in the past were incompatible with the MPA's objectives (Cadiou et al. 2008). Trawling and spear-fishing is banned everywhere inside the MPA.

Monitoring of professional fishing inside the PortCros MPA from 2001 to 2005 (Cadiou et al. 2008) revealed that the mean number of signatory fishermen is about $19 \mathrm{yr}^{-1}$, but the number of fishing vessels observed in the MPA ranges between 9 and 13 . Thus, nearly half of the signatory fishermen do not actually fish within the MPA. Fishing vessels, usually operated by the owner, are small $(8.6 \mathrm{~m}$ length on average) and have low engine power ( $93 \mathrm{~kW}$ on average). Trammel nets represent about $84 \%$ of the gear types used. Professional fishing is uniformly distributed throughout the fishing areas of the MPA $(95 \%$ of the surface), but the MPA generally represents a maximum of about $50 \%$ of their total fishing grounds, and fishing vessels spend a maximum of about $25 \%$ of their total fishing time inside the MPA (Cadiou et al. 2008).

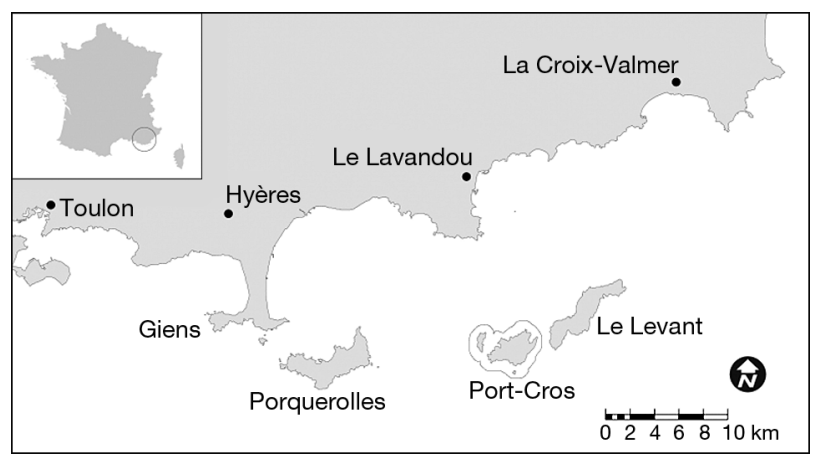

Fig. 1. Port-Cros National Park's marine protected area 


\section{The Ecopath model}

Principles and equations of Ecopath

The Ecopath model (Christensen \& Pauly 1992, Christensen \& Walters 2004) is a mass-balanced model describing the feeding relationships between functional groups, defined as ecologically similar life-stage, species, or groups of species (similar sizes, diets, predators, and life cycles). The Ecopath model is a snapshot of the ecosystem structure and assumes that, for each functional group $i$, production is equal to the sum of the biomass removed by nonpredation natural causes (diseases, old age,...), predation, and fishing, plus net migration and biomass accumulation:

$$
P_{i}=M 0_{i} \times B_{i}+M 2_{i} \times B_{i}+Y_{i}+N M_{i}+B A_{i}
$$

where $P_{i}$ is production $\left(\mathrm{t} \mathrm{km}^{-2} \mathrm{yr}^{-1}\right), B_{i}$ is biomass $\left(\mathrm{t} \mathrm{km}^{-2}\right), M 0_{i}$ is non-predation natural mortality rate $\left(\mathrm{yr}^{-1}\right), M 2_{i}$ is predation natural mortality rate $\left(\mathrm{yr}^{-1}\right), Y_{i}$ is catch $\left(\mathrm{t} \mathrm{km}^{-2} \mathrm{yr}^{-1}\right), N M_{i}$ is net migration $\left(\mathrm{t} \mathrm{km}^{-2} \mathrm{yr}^{-1}\right)$, and $B A_{i}$ is biomass accumulation $\left(\mathrm{t} \mathrm{km}^{-2} \mathrm{yr}^{-1}\right)$. This equation can also be formulated for each functional group:

$$
\begin{aligned}
P / B_{i} & \times B_{i}=P / B_{i} \times B_{i} \times\left(1-E E_{i}\right) \\
& +\Sigma_{j}(Q / B)_{j i} \times B_{i} \times D C_{j i}+Y_{i}+N M_{i}+B A_{i}
\end{aligned}
$$

where production is expressed as the product between the production/biomass ratio $\left(P / B_{i}, \mathrm{yr}^{-1}\right)$ and the biomass; non-predation natural mortality is expressed through ecotrophic efficiency ( $E E$, dimensionless), which is the part of the production used by the trophic web, exported, accumulated, or fished; and predation is expressed as the product of the biomass, the consumption/biomass ratio $\left(Q / B_{j i 1} \mathrm{yr}^{-1}\right)$, and the sum of the diet compositions $D C_{j i}$ of all the predator groups $j$ which feed partly on prey $i$.

\section{Functional groups definition}

The model we built represents an average situation of the Port-Cros MPA for the period 1998 to 2008, and comprises 41 functional groups, including detritus (Table 1). Fish functional groups were based on a list of 85 species observed in Port-Cros (Dufour et al. 2007). Species were aggregated according to their trophic level (TL) (Stergiou \& Karpouzi 2002), maximum length $\left(L_{\max }, \mathrm{cm}\right)$ (Froese \& Pauly 2009), and feeding type (e.g. carnivorous, omnivorous, herbivorous). Thus, we obtained 18 fish groups, including 2 mono-specific groups (for dusky grouper Epinephe- lus marginatus and salema Sarpa salpa), which were split into ontogenic groups, to account for changes in their diet with age. Fish groups were named using the most abundant species of the group, a ' + ' indicating the presence of secondary species (Table S1 in the supplement at www.int-res.com/articles/suppl/ m456p201.pdf).

Twenty-two groups of invertebrates were defined, based on descriptions of fish stomach contents, to organize the main fish prey in homogeneous groups (Table 1). In spite of limited available data, the invertebrates were split into quite detailed groups, especially for echinoderms or crustaceans, as they include quite diverse organisms. No marine mammals or sharks were included because of the small size of the MPA, a negligible area for these species, and because they were rarely observed inside the MPA. However, the Port-Cros National Park islands shelter significant populations of seabirds (Cory's shearwater Calonectris diomedea, yelkouan shearwater Puffinus yelkouan, and yellow-legged gull Larus cachinnans michahellis), which were included in the model. Among primary producers, seagrass Posidonia oceanica was distinguished from seaweeds, and shallow seaweeds from deep seaweeds, since they are not grazed upon by the same predators.

\section{Estimates of biomass, diet, and catch per group}

Fish biomass was obtained from diving counts and scientific trawling, in Port-Cros, from 1981 to 2008 (mainly from Khoury 1987, Francour 1997 and Ruitton et al. 2004). Biomass of the other (non-fish) groups was collected from different surveys conducted in or near Port-Cros (e.g. Francour 1990). For each species, the calculation of biomass accounted for the surface of its habitat types inside the MPA, estimated from recent cartography in the Port-Cros National Park (Belsher et al. 2005) (Tables S2 \& S3 in the supplement). For a few groups, in the absence of available data in the literature, biomass was estimated from expert advice or as part of the massbalanced calculations of Ecopath.

Fish diet compositions were collected from published stomach contents analysis, mainly in the north-western Mediterranean Sea. Most data came from 2 studies realized on seagrass meadows of Posidonia oceanica, in the Marseille (Bell \& HarmelinVivien 1983) and Port-Cros regions (Khoury 1987), in the 1980s. Diet compositions for most of the other groups were based on 2 Ecopath models available in 
Table 1. Parameters of the balanced Ecopath model of the Port-Cros marine protected area (Hypothesis 0) by functional group (values in bold were estimated by Ecopath). Fish groups were named using the most abundant species of the group, a ' + ' indicating the presence of secondary species. TL: trophic level (dimensionless); $B$ : biomass $\left(\mathrm{t} \mathrm{km}^{-2} \mathrm{yr}^{-1}\right)$; $M$ : natural mortality rate $\left(\mathrm{yr}^{-1}\right) ; F$ : fishing mortality rate $\left(\mathrm{yr}^{-1}\right) ; P / B$ : production/biomass $\left(\mathrm{yr}^{-1}\right) ; Q / B$ : consumption/biomass $\left(\mathrm{yr}^{-1}\right) ; E E$ : ecotrophic efficiency (dimensionless); $P / Q$ : production/consumption (dimensionless): OI: omnivory index (dimensionless); $Y$ : landings (t km ${ }^{-2}$ $\mathrm{yr}^{-1}$ ); Access.: accessibility to fishing (dimensionless; accessibility is defined as the fraction of the biomass group that can be caught increasing indefinitely the current fishing effort). Dashes represent no input values (either no fishing so no $F$ or $Y$, or $Q / B$ calculated directly without estimating $M$ and $F$ )

\begin{tabular}{|c|c|c|c|c|c|c|c|c|c|c|c|c|}
\hline & Group name & $T L$ & $B$ & $M$ & $F$ & $P / B$ & $Q / B$ & $E E$ & $P / Q$ & $O I$ & $Y$ & Access. \\
\hline 1 & Seabirds & 4.09 & 0.29 & - & - & 0.40 & 73.20 & 0.000 & 0.01 & 0.43 & - & 0.0 \\
\hline 2 & Rays & 4.38 & 0.03 & 0.20 & - & 0.20 & 1.99 & 0.400 & 0.10 & 0.53 & 0.0030 & 1.0 \\
\hline 3 & Dusky grouper-large & 4.37 & 4.32 & 0.10 & - & 0.10 & 0.67 & 0.000 & 0.15 & 0.27 & - & 0.0 \\
\hline 4 & Dusky grouper-medium & 4.25 & 0.43 & 0.44 & 0.0003 & 0.44 & 1.56 & 0.721 & 0.28 & 0.28 & 0.0001 & 1.0 \\
\hline 5 & Dusky grouper-small & 3.98 & 0.25 & 1.53 & 0.0003 & 1.53 & 4.40 & 0.396 & 0.35 & 0.32 & 0.0001 & 1.0 \\
\hline 6 & Amberjack+ & 4.08 & 5.55 & 0.24 & 0.0052 & 0.24 & 2.44 & 0.108 & 0.10 & 0.33 & 0.0290 & 0.6 \\
\hline 7 & Red scorpionfish+ & 4.21 & 0.49 & 0.36 & 0.1598 & 0.52 & 4.48 & 0.666 & 0.12 & 0.31 & 0.0790 & 1.0 \\
\hline 8 & Scorpionfishes+ & 3.79 & 4.29 & 0.59 & 0.0072 & 0.60 & 3.99 & 0.290 & 0.15 & 0.26 & 0.0310 & 0.8 \\
\hline 9 & Surmullet+ & 3.65 & 0.24 & 0.71 & 0.1280 & 0.84 & 5.65 & 0.962 & 0.15 & 0.43 & 0.0300 & 0.1 \\
\hline 10 & Pipefishes+ & 3.41 & 0.02 & 1.38 & - & 1.38 & 9.92 & 0.829 & 0.14 & 0.33 & - & 0.0 \\
\hline 11 & Wrasses & 2.96 & 5.04 & 0.52 & 0.0038 & 0.53 & 5.27 & 0.951 & 0.10 & 0.47 & 0.0190 & 0.8 \\
\hline 12 & Gobies & 3.33 & 0.43 & 1.12 & - & 1.12 & 5.60 & 0.784 & 0.20 & 0.13 & - & 0.0 \\
\hline 13 & Pagellus & 3.66 & 0.65 & 0.41 & - & 0.42 & 4.15 & 0.980 & 0.10 & 0.28 & 0.0030 & 1.0 \\
\hline 14 & Diplodus+ & 3.08 & 3.63 & 0.49 & 0.0080 & 0.50 & 5.03 & 0.660 & 0.10 & 0.18 & 0.0290 & 0.8 \\
\hline 15 & Blennies+ & 3.32 & 0.15 & 0.59 & - & 0.59 & 5.94 & 0.978 & 0.10 & 0.27 & - & 0.0 \\
\hline 16 & Horse mackerels+ & 3.54 & 20.00 & 0.56 & 0.0004 & 0.56 & 5.56 & 0.917 & 0.10 & 0.68 & 0.0120 & 0.1 \\
\hline 17 & Mullets & 2.27 & 4.50 & 0.45 & - & 0.45 & 4.53 & 0.595 & 0.10 & 0.22 & - & 0.0 \\
\hline 18 & Salema-adults & 2.00 & 5.40 & 0.25 & 0.0421 & 0.25 & 2.54 & 0.126 & 0.10 & 0.00 & 0.0220 & 1.0 \\
\hline 19 & Salema-small & 2.00 & 4.10 & 0.81 & 0.0421 & 0.81 & 5.24 & 0.425 & 0.16 & 0.00 & 0.0200 & 1.0 \\
\hline 20 & Cephalopods & 3.60 & 3.00 & - & - & 2.34 & 7.80 & 0.948 & 0.30 & 0.18 & 0.0170 & 0.8 \\
\hline 21 & Crabs & 2.63 & 3.61 & - & - & 1.61 & 14.00 & 0.755 & 0.12 & 0.45 & 0.0190 & 0.2 \\
\hline 22 & Decapods & 2.67 & 13.37 & - & - & 2.30 & 23.00 & 0.950 & 0.10 & 0.37 & 0.0120 & 0.2 \\
\hline 23 & Bivalves & 2.10 & 2.79 & - & - & 2.46 & 15.87 & 0.939 & 0.16 & 0.09 & - & 0.0 \\
\hline 24 & Gastropods & 2.24 & 17.89 & - & - & 1.91 & 10.71 & 0.900 & 0.18 & 0.26 & - & 0.0 \\
\hline 25 & Sea stars & 2.71 & 0.70 & - & - & 0.25 & 1.67 & 0.184 & 0.15 & 0.36 & - & 0.0 \\
\hline 26 & Brittle stars+ & 2.05 & 0.69 & - & - & 0.49 & 3.24 & 0.900 & 0.15 & 0.06 & - & 0.0 \\
\hline 27 & Sea urchins & 2.16 & 38.20 & - & - & 0.19 & 1.27 & 0.651 & 0.15 & 0.18 & - & 0.0 \\
\hline 28 & Sea cucumbers & 2.05 & 76.26 & - & - & 0.25 & 1.67 & 0.232 & 0.15 & 0.05 & - & 0.0 \\
\hline 29 & Sea worms & 2.33 & 27.59 & - & - & 1.82 & 11.53 & 0.950 & 0.16 & 0.31 & - & 0.0 \\
\hline 30 & Suspensivores & 2.28 & 24.83 & - & - & 1.70 & 14.01 & 0.900 & 0.12 & 0.23 & - & 0.0 \\
\hline 31 & Gorgonians & 2.23 & 40.56 & - & - & 0.08 & 0.53 & 0.000 & 0.15 & 0.29 & - & 0.0 \\
\hline 32 & Small crustaceans & 2.14 & 31.05 & - & - & 4.00 & 33.40 & 0.925 & 0.12 & 0.13 & - & 0.0 \\
\hline 33 & Amphipods & 2.24 & 21.79 & - & - & 4.00 & 20.00 & 0.950 & 0.20 & 0.20 & - & 0.0 \\
\hline 34 & Large zooplankton & 3.04 & 2.18 & - & - & 25.00 & 125.0 & 0.950 & 0.20 & 0.09 & - & 0.0 \\
\hline 35 & Small zooplankton & 2.10 & 9.63 & - & - & 50.00 & 170.0 & 0.950 & 0.29 & 0.09 & - & 0.0 \\
\hline 36 & Foraminifera & 2.00 & 4.80 & - & - & 80.00 & 266.7 & 0.950 & 0.30 & 0.00 & - & 0.0 \\
\hline 37 & Posidonia & 1.00 & 8550.0 & - & - & 0.30 & - & 0.303 & - & 0.00 & - & 0.0 \\
\hline 38 & Shallow seaweeds & 1.00 & 141.00 & - & - & 4.43 & - & 0.533 & - & 0.00 & - & 0.0 \\
\hline 39 & Deep seaweeds & 1.00 & 40.95 & - & - & 1.57 & - & 0.559 & - & 0.00 & - & 0.0 \\
\hline 40 & Phytoplankton & 1.00 & 20.00 & - & - & 112.6 & - & 0.677 & - & 0.00 & - & 0.0 \\
\hline 41 & Detritus & 1.00 & 86.35 & - & - & - & - & 0.533 & - & 0.39 & - & 0.0 \\
\hline
\end{tabular}

the literature (Opitz 1996, Pinnegar 2000) (Table S4 in the supplement).

Catch data came from annual monitoring of the professional fishing fleet inside the Port-Cros MPA (Cadiou \& Bonhomme 2006). The last year (2005) was identified as a representative year, and the corresponding catch data were used (Table 1). Only the biomass caught inside the MPA and reported in fishermen's logbooks was considered. Catch included landings of the targeted and bycatch species, and we assumed there was no discard from this traditional small-scale coastal fishery.

\section{$P / B$ and $Q / B$ Ecopath parameters}

Ecopath parameters of fish groups were calculated with empirical equations. Fish production per 
unit biomass $P / B$ corresponds to the total mortality rate $Z$ (Allen 1971), the sum of natural $(M)$ and fishing $(F)$ mortality rates. $M$ was calculated by averaging the results of 3 empirical equations (Pauly 1980, Hoenig 1993, Gascuel et al. 2008). $F$ is the catch to biomass ratio. Fish consumption per unit biomass $Q / B$ was calculated with an empirical equation (Palomares \& Pauly 1998) (Table S5 in the supplement). Compilations of growth parameters and length-weight relationships are less systematic and generally not available for invertebrates, so their $P / B$ and $Q / B$ values were collected from the literature (Table S3), preferably from Port-Cros (Francour 1990) or from the best values compiled in 3 previous Ecopath models (Opitz 1996, Pinnegar 2000, Coll et al. 2006).

\section{Balancing the Ecopath model}

The logic applied during the balancing step was based on model structure and data quality, as recommended by Link (2010). Missing estimates of parameters for some groups were compensated by setting complementary parameters to realistic values in the production equation. For instance, the few groups for which biomass was missing were attributed a reasonable value of $E E$ (low $E E$ values for high trophic level groups and higher $E E$ values for lower trophic level groups), and the corresponding biomass was left to be calculated by Ecopath. Note that none of these groups are directly concerned by the model exploration described with Hypotheses 1 to 3 (see 'Potential emigration and biomass accumulation'). Similarly, the production/ consumption ratio $(P / Q$, dimensionless), which generally ranges from 0.1 to 0.3 , was set to a fixed value to obtain the missing $Q / B$ values. The Ecopath model is balanced once $E E$ is equal or lower than 1 for all the groups.

Balancing the model required the modification of some input values in 3 steps (see 'Balancing the Ecopath model' in the supplement). First, it was necessary to adjust some input $Q / B$ parameters that seemed to be unrealistically high. Then, although data on fish diet compositions were considered reliable, as they were collected for every species of each group, some adjustments were necessary. Finally, biomass estimates were corrected for 3 groups. Biomass of cephalopods and bivalves had to be increased to sustain predation, and biomass of horse mackerels+ had to be decreased to relieve pressure on lower trophic level prey.

\section{Using Ecopath to identify keystone species and estimate potential exports}

\section{Mixed trophic impact and index of keystoneness}

Direct and indirect interactions within the ecosystem were analyzed using the mixed trophic impact (MTI) routine of Ecopath, which assesses the relative impact of a slight increase in abundance of any group on the biomass of other groups in the food web (Christensen et al. 2005). The MTI index, scaled from -1 to 1 , was calculated for every group in the model.

Keystone species, defined as species whose structuring role in the food web is much higher than what could be expected from their relative biomass, were identified using the method developed by Libralato et al. (2006), based on the MTI matrix. Following this method, we obtained an estimate of the index of 'keystoneness' (KS) for every functional group (except detritus), although we only focused on the 10 functional groups that ranked highest on the KS index.

\section{Potential emigration and biomass accumulation}

In the absence of data, net migration and biomass accumulation were assumed to be equal to zero for all functional groups in the base model (Hypothesis 0) of the Ecopath model. Three other alternative hypotheses were tested by building 3 other models, based on the base model, to evaluate potential emigration or biomass accumulation for some groups and assess the spillover of the MPA to neighborhood areas. Hypothesis 1 assumes that all 12 groups identified as being able to emigrate (P. Francour pers. obs.) were characterized by high ecotrophic efficiencies $(E E=0.95)$, which means that the remaining production constitutes the maximum biomass exports for each of them. Such an assumption also implies that few fishes of these groups died for other reasons than predation (i.e. $M 0_{i}=0.05 \times P / B_{i}$ ), most of them being exported, exploited, or predated. Hypothesis 2 increases the amount of imported prey in the diet of amberjack+ (from 3 to $20 \%$ ), assuming this large predator group could feed regularly outside the MPA (P. Francour pers. obs.). This hypothesis evaluates the sensitivity of the initial estimate of potential emigration to changes in predation pressure from amberjack+. Finally, Hypothesis 3 assumes that the net migration of large dusky grouper is null, to estimate the maximum biomass accumulation of large dusky grouper under a high $E E(=1)$. We thus assumed that all non-predated and unexploited groupers con- 
tribute to the accumulation of biomass (i.e. $M 0_{i}=0$ ). The estimated value was then compared to field observations. Indeed, large dusky groupers are known to be sedentary as they grow older, staying in holes and ambushing their prey. Thus, this group is unlikely to emigrate outside the MPA and would likely accumulate biomass over time.

\section{The EcoTroph model}

\section{Principles and equations of EcoTroph}

The ecological effects of the Port-Cros MPA were assessed using various hypothetical fishing scenarios with EcoTroph (Gascuel 2005, Gascuel et al. 2011). This trophic-level-based ecosystem modeling approach is founded on the idea that an ecosystem can be represented by its biomass distribution across trophic levels, this distribution being called the biomass trophic spectrum. Similar trophic spectra can also be built for other parameters, such as production or catch, and the EcoTroph model simulates the spectra distortions induced by fishing (see 'The EcoTroph model: principles and major equations' in the supplement).

\section{EcoTroph parameterization}

The reference state of the EcoTroph model was defined using the base Ecopath model (Hypothesis 0), assumed to represent the current state of the PortCros ecosystem. First, using the 'transpose' routine described in Gascuel et al. (2009), biomass $B_{i}$, production $P_{i}$, and catches $Y_{i}$ of each functional group $i$ were distributed over a range of trophic classes around the mean trophic level of the group (estimated by Ecopath). The omnivory indices $O I_{j}$ for each predator $j$ (Table 1) were used to measure the within-group variability in trophic levels and check the distribution of omnivory across trophic levels and functional groups. Omnivory indices were calculated as:

$$
O I_{j}=\sum_{i=1}^{n}\left(T L_{i}-\left(T L_{j}-1\right)\right)^{2} \times D C_{j i}
$$

where $T L_{i}$ and $T L_{j}$ are the trophic levels of prey $i$ and predator $j$ and $D C_{j i}$ is the proportion of prey $i$ in the diet of predator $j$ (Christensen et al. 2008).

Accessibility to fishing was defined for each functional group according to the importance of targeted species within the group (if the group is not fished, the accessibility value is zero) (see Table 1). Then, trophic spectra of $B, P$, and $Y$ were calculated by trophic level by summing the related parameter over all functional groups. So, the EcoTroph model represents the current biomass, production, and catch by trophic class, whereas they are considered by functional group in the Ecopath model.

\section{Simulation of fishing scenarios}

Starting from the reference state, different scenarios of fishing mortality were simulated using the 'diagnosis' routine (Gascuel et al. 2009). Thus, the current state of the protected ecosystem was compared to those resulting from the different fishing scenarios, based on the biomass and catch trophic spectra and the mean trophic level of the ecosystem. First, the fishing mortalities $F^{*}$ were set to 0 to evaluate how far from the unexploited state the ecosystem is. Then, 3 hypothetical scenarios of exploitation were built, all with higher fishing mortality than the current one, intending to cover a large range of realistic exploitation patterns that would have occurred when fishing was less restricted in the MPA (Fig. 2).

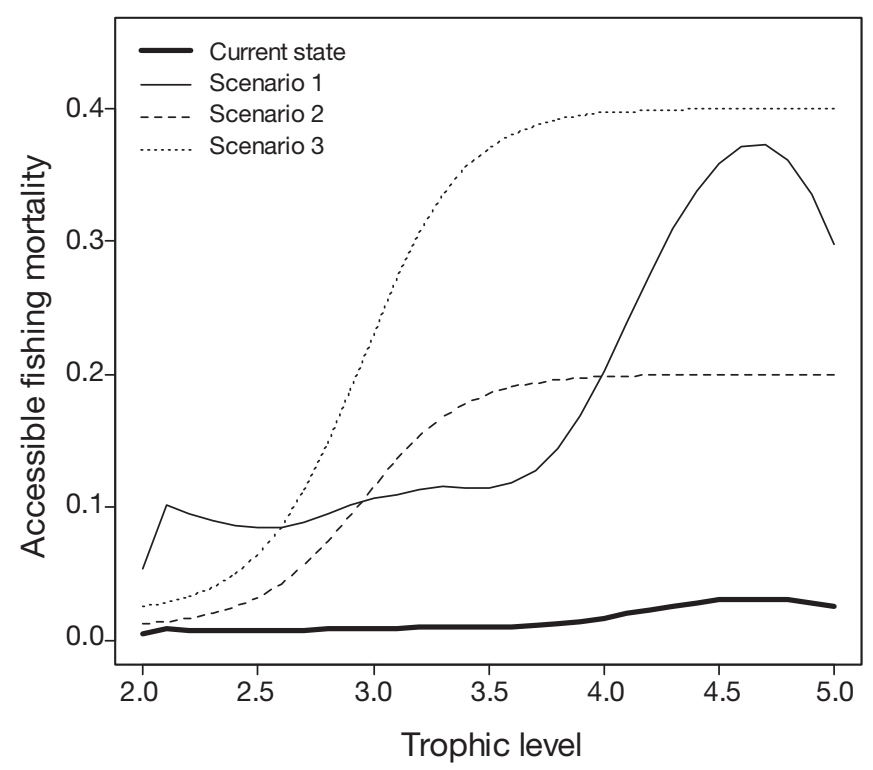

Fig. 2. Trophic spectra of accessible fishing mortality $F^{*}$ $\left(\mathrm{yr}^{-1}\right)$, calculated for the current state (thick line) and simulated for the 3 fishing scenarios (thin lines). Scenario 1 simulates a 12 -fold increase in the current fishing mortality, obtained by applying to the current $F^{*}{ }_{\tau}$ an effort multiplier (m) of 12, and corresponding to a 10-fold increase in the current catch, up to $3.2 \mathrm{t} \mathrm{km}^{-2}$ (the maximal level of catch observed inside the reserve in the past). Scenarios 2 and 3 featured a fixed $F^{*}{ }_{\tau}$ value set to 0.2 and 0.4 , respectively, for trophic levels above 3.5, and low trophic levels, even if accessible, were assumed not targeted using a fishing mortality which follows a logistic curve, with a trophic level at first catch set at 3 


\section{RESULTS}

\section{General characteristics of the Port-Cros MPA ecosystem}

Biomass, trophic level, and omnivory index

Total biomass in the MPA was estimated by Ecopath at about $9000 \mathrm{t} \mathrm{km}^{-2}$. The model provided biomass estimates for all groups, including some invertebrates which were previously poorly documented (Table 1). The biomass of first-order producers was largely dominated by the group Posidonia, whose abundance was especially high in the Port-Cros MPA (8550 t km², that is to say $95 \%$ of the total biomass). Secondary producers were more diverse and mainly represented by benthic groups whose abundances were similar (e.g. sea cucumbers, gorgonians, sea urchins, sea worms, and suspensivores). As expected, biomass decreased as trophic level increased (Fig. 3a). However, some fish groups with high trophic level also had relatively high biomass, such as amberjack $+\left(5.6 \mathrm{t} \mathrm{km}^{-2}\right)$ or large dusky grouper $\left(4.3 \mathrm{t} \mathrm{km}^{-2}\right)$. Fish of intermediate trophic level were dominated by horse mackerels+.

No significant relationship was found between $O I$ and $T L$, except for the lowest trophic levels (Fig. 3b). Indeed, by definition, $O I$ is constrained to zero for groups feeding on one single trophic level such as strictly herbivorous consumers that will only eat on $T L$ 1. OI rapidly increased from TL 2 to 2.5, as additional prey were added to the diet, and varied be- tween 0.2 and 0.5 for most groups whose mean $T L$ was $>2.5$. Such a result reflects a high trophic opportunism in functional groups, whose prey covered a wide range of trophic levels. This suggests that $O I_{\text {, }}$ which measures the variability between prey types, is a good indicator of dispersion of predation across trophic levels (Libralato \& Solidoro 2010) and justifies the use of $O I$ in the 'transpose' routine of EcoTroph. However, the relatively low $O I$ value obtained for large zooplankton could in part be a modeling artifact, all prey of this group being merged in the small zooplankton group (for convenience and also because of data limitation on invertebrate species diets). Gobies also had a low OI, because of their small size, that restricts their choice of prey at low trophic levels. Conversely, the OI of horse mackerels+ was very high because of the large variety of prey found in stomach content analyses.

\section{Keystone species of the Port-Cros ecosystem}

Results estimating trophic impact with the MTI routine of Ecopath highlighted the central role played by both the large dusky grouper and amberjack+ groups, even if the latter was also impacted by large dusky grouper (Fig. 4). An increase in large dusky grouper biomass would have an indirect positive impact on horse mackerelst, caused by the decrease of red scorpionfish+, one of the main predators of horse mackerels+. Similarly, large dusky
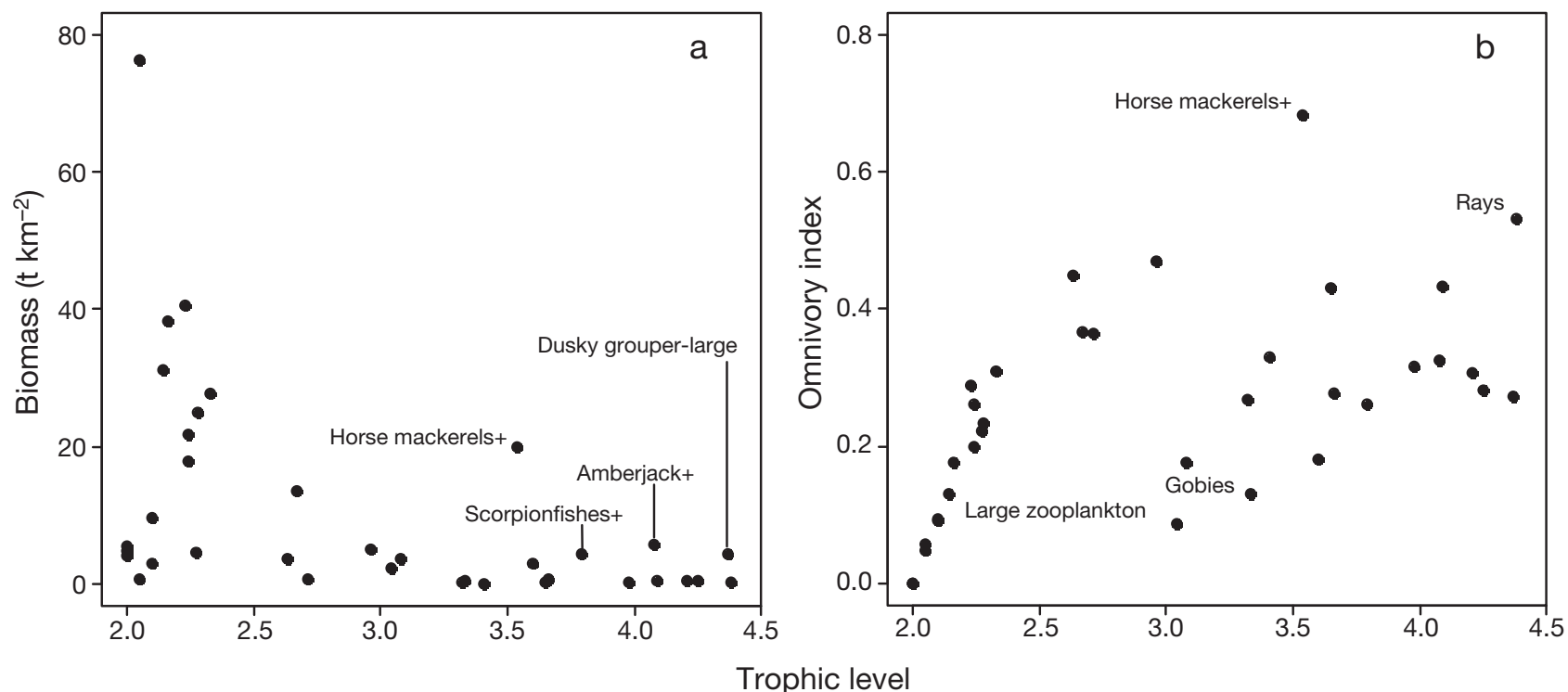

Fig. 3. Relationship between (a) biomass, $B\left(\mathrm{t} \mathrm{km}^{-2}\right.$ ) or (b) omnivory index, OI (dimensionless) and trophic level TL (dimensionless). Dots are values obtained for each functional group from the Ecopath model. ' + ' indicates the presence of secondary species 


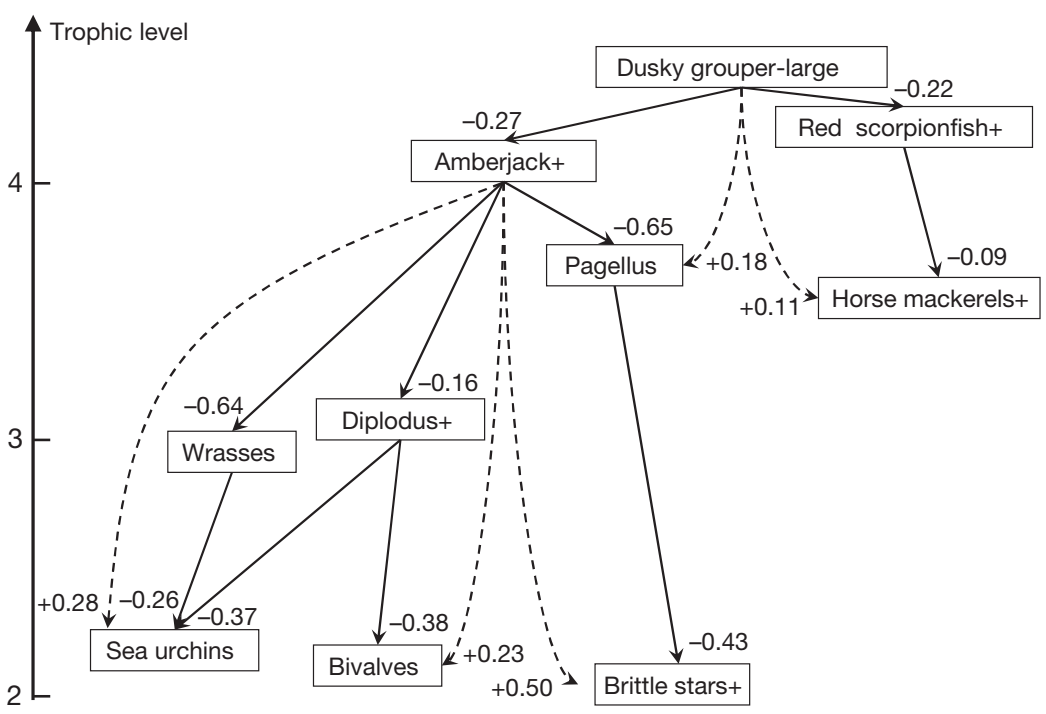

Fig. 4. Diagram of trophic cascades identified through mixed trophic impact (MTI) analysis. Thick arrows represent direct negative impact by predation; dotted arrows represent indirect positive impact in the form of trophic cascades. MTI index values (dimensionless) are indicated next to each arrow

grouper would have an indirect positive impact on pagellus, due to the decrease of amberjack+. Moreover, an increase in amberjack+ biomass would have an indirect positive impact on some invertebrate groups (bivalves, brittle stars+, and sea urchins), due to the decrease of one of their fish predators (diplodus+, pagellus, and wrasses) (see Fig. 4 for detailed values of MTI).

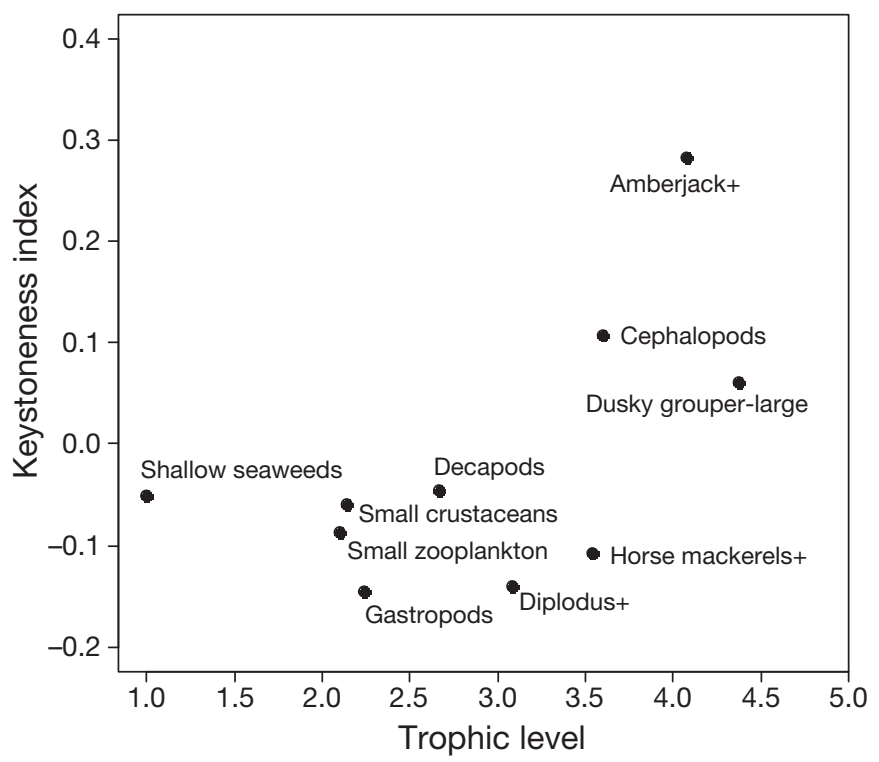

Fig. 5. Keystoneness index $K S$ (dimensionless) for the 10 functional groups that ranked highest. For each group (each dot), the $K S$ index (y-axis) is reported against trophic level $T L$ (dimensionless) ( $x$-axis)
The KS index confirmed the importance of large dusky grouper, which ranked third, but also showed the key role of amberjack+ and cephalopods in the ecosystem (Fig. 5). Amberjack+, whose trophic role was also illustrated in Fig. 4, ranked first, as this group controls the abundance of important species such as pagellus and wrasses. Cephalopods ranked second, perhaps because they feed on various fish groups. Note that the positive or negative sign of the KS index does not matter; only the relative values of $\mathrm{KS}$ are considered. We also note that the group Posidonia, in spite of its large abundance, seemed to have little trophic impact on the ecosystem. Among primary producers, shallow seaweeds ranked first, perhaps because of their importance in the diet of several fish groups and particularly for small salema.

\section{Estimating MPA effects}

\section{Effects outside the reserve}

Under Hypothesis 1 (with EE set up to 0.95), the potential (i.e. maximum) emigration of the Port-Cros ecosystem was estimated at $7.7 \mathrm{t} \mathrm{km}^{-2} \mathrm{yr}^{-1}$, i.e. about $100 \mathrm{t} \mathrm{yr}^{-1}$ for the total area of the MPA (Table 2). This also means that up to $25 \%$ of the total production of the 12 groups identified as being able to emigrate (i.e. $32 \mathrm{t} \mathrm{km}^{-2} \mathrm{yr}^{-1}$ ) could be exported outside the reserve. The highest emigration potential was obtained for salema, scorpionfishes+, and amberjack+, for which $>50 \%$ of the production is available for emigration given the model structure. Because fish groups that can emigrate represent only a small fraction of the entire ecosystem, the potential emigration was low compared to the whole ecosystem production value (Fig. 6). Nevertheless, the Ecopath model suggested that the part of the production potentially exported increases with trophic level, from $<0.1 \%$ for low trophic levels to $>1 \%$ around TL 4. Under Hypothesis 2 (with $20 \%$ of imports in amberjack+'s diet), the decreased predation pressure resulted in a slight increase in potential emigration for TL 2.5 to 5, compared to that of Hypothesis 1 (Fig. 6). Lower predation on the prey of amberjack+ (e.g. scorpionfishes+, diplodus+, horse mackerels+, and cephalopods), resulted in a larger part of the production from these 
Table 2. Production $P$ and potential emigration estimates (per surface unit in

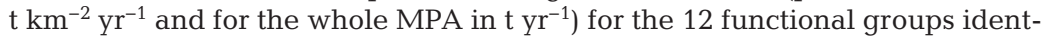
ified to be able to emigrate outside the reserve (Version 1 of the Ecopath model)

\begin{tabular}{|llccc|}
\hline & Group name & Per surface unit & For the whole MPA \\
& $P$ & $\begin{array}{c}\text { Potential } \\
\text { emigration }\end{array}$ & $\begin{array}{c}\text { Potential } \\
\text { emigration }\end{array}$ \\
\hline 2 & Rays & 0.007 & 0.004 & 0.05 \\
4 & Dusky grouper-medium & 0.188 & 0.043 & 0.55 \\
5 & Dusky grouper-small & 0.376 & 0.209 & 2.69 \\
6 & Amberjack+ & 1.354 & 1.140 & 14.68 \\
7 & Red scorpionfish+ & 0.254 & 0.072 & 0.93 \\
8 & Scorpionfishes+ & 2.572 & 1.698 & 21.87 \\
14 & Diplodus+ & 1.825 & 0.529 & 6.81 \\
16 & Horse mackerels+ & 11.120 & 0.366 & 4.71 \\
17 & Mullets & 2.039 & 0.724 & 9.33 \\
18 & Salema-adults & 1.372 & 1.131 & 14.57 \\
19 & Salema-small & 3.339 & 1.753 & 22.58 \\
20 & Cephalopods & 7.020 & 0.015 & 0.19 \\
& Total & 31.465 & 7.684 & 98.97 \\
\hline
\end{tabular}

\section{EcoTroph simulation: fishing scenarios}

Based on EcoTroph scenarios, the ecosystem inside the Port-Cros MPA is currently very close to the unexploited state (Table 3 and Fig. 8a,b), with its total biomass being lower by about $0.2 \%$ and the biomass of its top predators $(T L \geq 3.5)$ by about $2 \%$ only. The relative biomass trophic spectra also revealed that trophic levels >4 (the only ones currently impacted by fishing) showed a small decrease (about $3 \%$ ) in their biomass in the current state, compared to the unexploited one. No change was observed in the mean TL of the top predators or that of total biomass. Thus, current fishing practices did not seem to have a significant impact

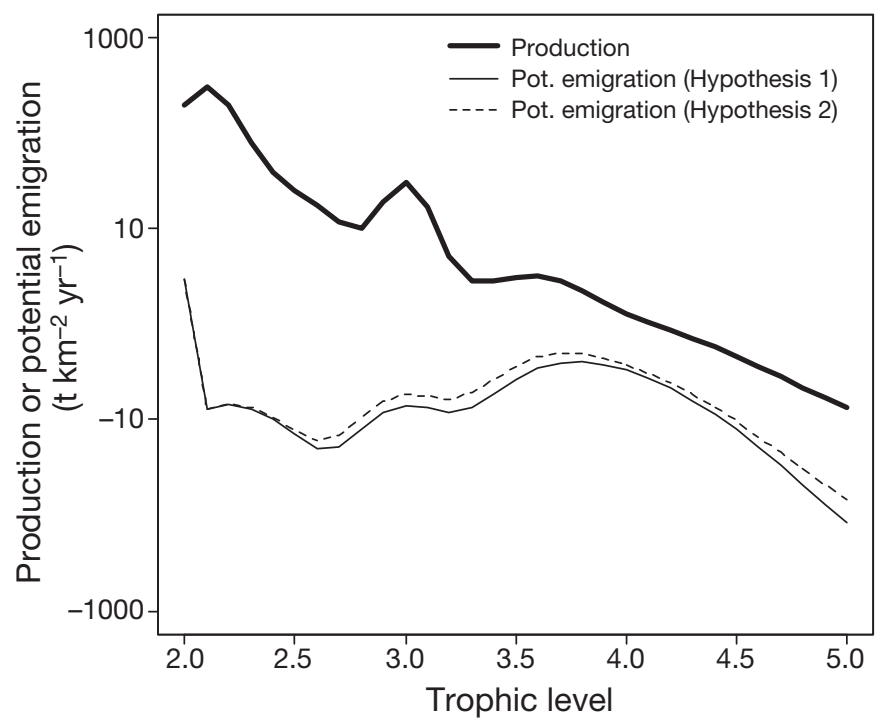

Fig. 6. Trophic spectra of production $P\left(\mathrm{t} \mathrm{km}^{-2} \mathrm{yr}^{-1}\right)$ (thick line) and potential emigration $\left(\mathrm{t} \mathrm{km}^{-2} \mathrm{yr}^{-1}\right)$ (thin lines). Thin solid line represents potential emigration estimated under Hypothesis 1 ( $3 \%$ of imports in diet for amberjack + ), and dashed line, Hypothesis 2 (20\% of imports in diet for amberjack+) of the Ecopath model

prey available for emigration (although the level of change is relatively low, compared to changes in the proportion in the diet). Under Hypothesis 3, the maximum biomass accumulation rate for large dusky grouper was estimated at $10 \% \mathrm{yr}^{-1}$, which was consistent with the mean annual increase rate of about $13 \%$ observed over the last decade in Port-Cros (Fig. 7). on the Port-Cros MPA ecosystem.

As expected, the simulated fishing scenarios, from the unexploited state to high fishing rates, showed that biomass and mean trophic levels decreased as total catches increased (Table 3). Although low trophic levels represented the main part of the biomass, they were exploited at a very low rate in the current state, and, hence, the decrease in total biomass went up to $3 \%$ only in the highest fishing scenario (Scenario 3) (Fig. 8). In addition, low trophic levels were characterized by a high productivity and

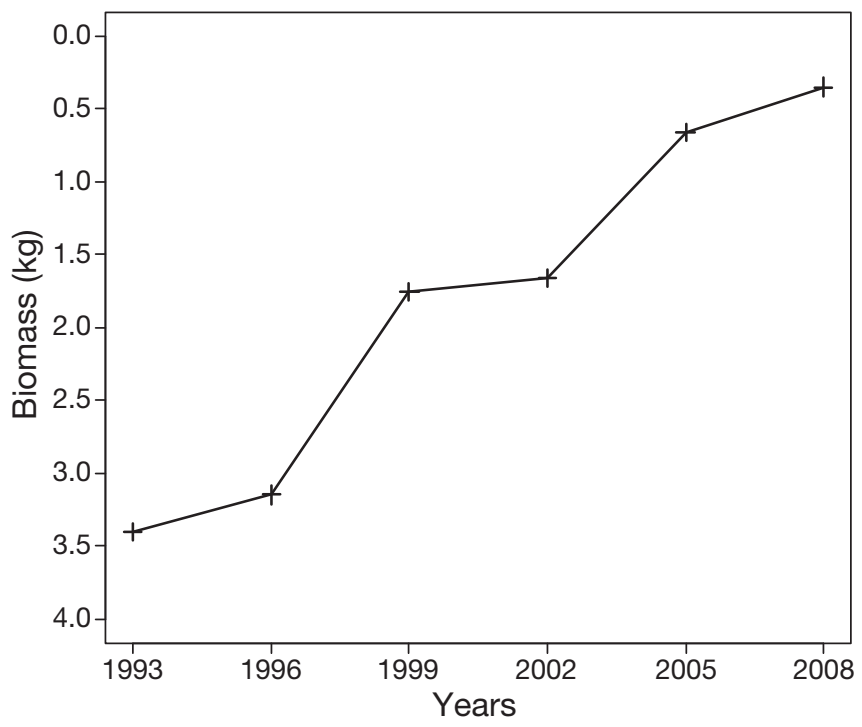

Fig. 7. Biomass $B(\mathrm{~kg})$ calculated from counts of large dusky grouper Epinephelus marginatus (from 65 to $120 \mathrm{~cm}$ in length) at Port-Cros from 1993 to 2008 (Harmelin 2007) 


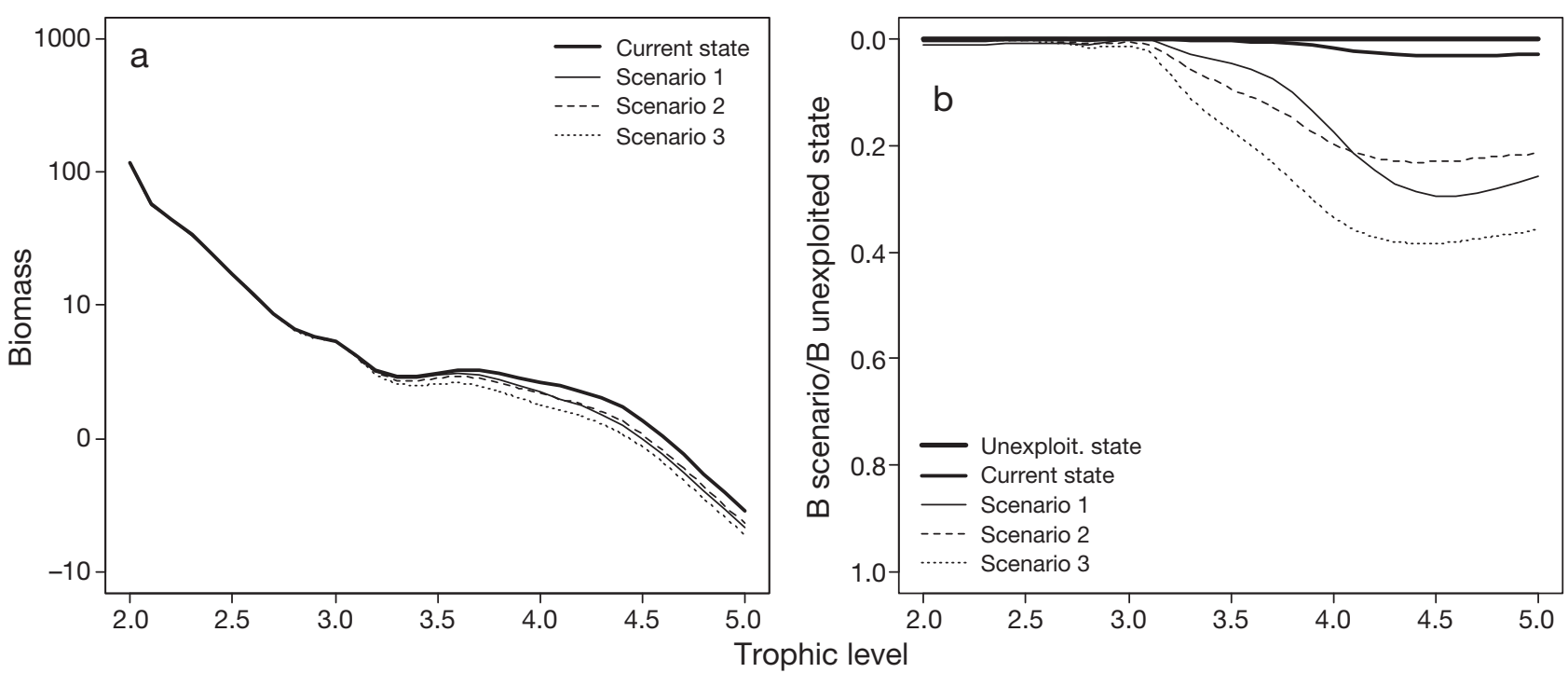

Fig. 8. Trophic spectra of (a) absolute biomass (in t) and (b) relative biomass (dimensionless) by fishing scenario. Relative biomass was calculated by dividing absolute biomass values of each scenario by the absolute biomass values of the unexploited state

Table 3. Indicators obtained from the EcoTroph simulations to compare the unexploited and current states and the 3 scenarios of higher fishing effort. Indicators are biomass $B(\mathrm{t})$, catch $Y(\mathrm{t})$ and mean trophic level (mean $T L$, dimensionless), for the total ecosystem and for the predators whose $T L$ is $>3.5$

\begin{tabular}{|lccccc|}
\hline Indicators & $\begin{array}{c}\text { Unexploit. } \\
\text { state }\end{array}$ & $\begin{array}{c}\text { Current } \\
\text { state }\end{array}$ & Scenario 1 & Scenario 2 & Scenario 3 \\
\hline Total biomass & 379.6 & 378.7 & 370.4 & 372.8 & 368.0 \\
Predator biomass & 32.5 & 31.9 & 27.0 & 26.7 & 22.6 \\
$\begin{array}{l}\text { Total catches } \\
\text { Trophic level of } \\
\text { total biomass }\end{array}$ & - & 0.33 & 3.3 & 9.0 & 18.0 \\
$\begin{array}{l}\text { Trophic level of } \\
\text { predator biomass }\end{array}$ & 4.05 & 2.41 & 2.38 & 2.38 & 2.36 \\
\hline
\end{tabular}

based on the best available data. Although building the model required the use of data from the early 1980s to the late 2000s, two-thirds of the fish biomass data was collected between 2005 and 2008, and catch represented the year 2005, knowing that fishing effort has been stable inside the reserve since the 2000s (Cadiou et al. 2008). Moreover, the information on fish, collected by species, can be considered as accurate. The model describes an average state of the ecosystem for the years 1998 to 2008, but a fast turn-over, which made them more resilient to fishing. Conversely, higher fishing effort could potentially have more severe impacts on high trophic levels, causing a decrease in predator biomass that varies from 15 to $29 \%$, depending on the scenario (Table 3), and up to $40 \%$ for $T L>4$ (Fig. 8). The mean trophic level of total biomass decreased from 2.41 to 2.36 (Table 3), but the mean trophic level of predators appeared less affected because all of them are impacted in similar proportions.

\section{DISCUSSION}

\section{Modeling the trophic functioning of the Port-Cros MPA ecosystem}

The Ecopath model of the Port-Cros MPA constitutes a snapshot of the current state of the ecosystem using older diets, which may cause a bias since the protection from fishing may have resulted in changes in diets and dynamics that remain undetected here. For these reasons, the uncertainty of the true rate of recovery of dusky groupers remains important. Yet, the ecosystem model gives a representation of the trophic functioning of the Port-Cros MPA's ecosystem that is consistent with current knowledge. However, the lack of long-term monitoring of fish abundances made it impossible to fit the model predictions to historical data using Ecosim, the dynamic version of Ecopath (Walters et al. 1997), and to explore the mechanisms of changes in the ecosystem.

Nevertheless, the Ecopath model presented in the current study enables analyzing 2 important ecological issues: the interactions of top predators and potential for migrations. First, dusky grouper Epinephelus marginatus, an emblematic Mediterranean species in the Port-Cros region that emerged as ecologically 
significant in our model, is protected by a moratorium along the French coast (Bodilis et al. 2003). This protection is controversial, as an increase in abundance of this top predator could have potentially negative side-effects on other species, competitors, or prey. However, no correlation was found in previous studies between the abundance of dusky grouper and that of its competitors, suggesting that protecting dusky grouper does not have any negative impact on other top predators, such as amberjack Seriola dumerili or dentex Dentex dentex (A. Ganteaume unpubl. data). Our results suggest slightly more complex dynamics, where the large dusky grouper has an impact on amberjack+, although both groups are in position to control the main trophic cascades (Fig. 4).

Second, the model was initially built as a closed ecosystem without any migrations inside or outside the MPA for any species. Yet, because of the small size of the area, we can easily conceive that migrations of phytoplankton and fish in all phases (adult, juvenile, larva, or egg) could occur. In the process of balancing the model, reconciling the biomass of horse mackerels+ with that of its prey (zooplankton) notably posed the question of potential exchanges with areas outside the Port-Cros MPA. In fact, previous coarse observations suggested that importation of phytoplankton might occur (Harmelin 1987) and that juveniles of dusky grouper migrate inside the MPA where adults are concentrated (Chauvet \& Francour 1989, Bodilis et al. 2003). These observations suggest that the MPA is dependent on the importation of nutrients and recruits, in addition to that of the primary producers and groupers' recruitment. Besides, a large abundance of top predators, like the amberjack + group, in such a small area is likely sustained by partial feeding outside the reserve (which is the foundation of Hypothesis 2).

Finally, despite incomplete knowledge about fish movements in the Port-Cros region, our models highlight the low potential emigration of fish, as expected considering the size of the protected area $\left(13 \mathrm{~km}^{2}\right)$. Thus, biomass exports from the MPA would only have local significance, as they appear negligible compared to the whole biomass of the related fish stocks. So, a local increase in density would only benefit the fishermen in the immediate surroundings of the Port-Cros MPA. To this end, this type of MPA appears to be a very insufficient tool for the management of fish stocks. This is coherent with the results of several synthesis studies on marine reserves (e.g. Lester et al. 2009), concluding that, although small reserves may produce larger biomass, the optimal reserve size depends on the targeted species and reserve characteristics. For instance, the biomass of groupers has been shown to increase within small reserves because of their high site fidelity and the small size of their core activity areas that remain stable for several years (Afonso et al. 2011). Nevertheless, studies that include food web dynamics, fish movements, and spillover suggested that reserves should be large rather than small to balance the loss of fish due to spillover and the potential production inside the reserve (see discussion in Grüss et al. 2011). However, as our models do not assess the distance on which the biomass is exported, we will not discuss the usefulness of MPA networks for increasing biomass exports on a larger scale in order to really sustain fisheries.

\section{Identifying keystone species in the Port-Cros MPA}

The KS index values obtained in our study would be better interpreted as the representation of a predation effect, instead of the 'keystoneness' effect. A keystone species is one that plays a determinant role in the ecosystem in spite of its low abundance (Power et al. 1996). On the contrary, the keystone species identified in the Port-Cros MPA using the method proposed by Libralato et al. (2006) were relatively abundant top-predator groups (amberjack+ and large dusky grouper; see Table 1). This suggests a possible bias in the method. The fact that several groups such as decapods, gastropods, and small zooplankton were identified as keystone groups is also surprising and may be caused by the structure of the model itself. A model is generally built for one purpose, and, thus, it is often the case that important prey, not directly linked to the problematic, are grouped in a large biomass group such as zooplankton and crustaceans, which, in turn, exert overly large influence in the model. Besides, although it is agreed that seagrass is a structural species (Piraino et al. 2002), identifying seagrass as keystone is unexpected because the current version of the Ecopath model does not include any habitat effect or nontrophic functional relationship. The physical presence of seagrass as essential habitat providing refuge, nursery, spawning area, etc., is determinant for the type of species the ecosystem can support. Yet, only a small part of the biomass produced by seagrass is used in the food web, the remaining parts (mostly the roots) acting as carbon sinks.

Mills et al. (1993) defined another kind of keystone species, called the keystone modifiers, whose activities like grazing affect habitat features in the ecosys- 
tems. However, similarly, a species that controls seagrass, in spite of its small biomass, would not be identified as keystone in our model, because this relationship is not featured. For instance, we could hypothesize that the keystone modifiers in the Port-Cros MPA are sea urchins or salema Sarpa salpa, both grazers on Posidonia meadows. To confirm this hypothesis, we would need data on the past abundance of S. salpa and P. oceanica, before the creation of the MPA, when dusky grouper was fished and so less abundant. Indeed, Sala \& Zabala (1996) demonstrated that the population structure of the benthic herbivore sea urchin Paracentrotus lividus, a key species controlling dynamics of seaweeds and sea grass meadows in the Medes Island reserve, was determined by predation by fish, and so by the level of fishing effort, due to trophic cascade effects. The same type of trophic cascade is showed by the MTI analysis in our model, as wrasses and diplodus+ both have a quite significant negative impact on sea urchins (Fig. 4).

\section{Using trophic functioning modeling as a tool to evaluate MPA effects}

Evaluating whether MPAs reach their protection objectives or not requires a comparison of the ecosystems, either inside and outside the protected area or before and after the establishment of the protected areas. The latter type of analysis of changes induced by fishing reduction is impossible for all species in the Port-Cros National Park, because of the lack of information before the reserve was created. Yet, previous studies concluded that the emblematic dusky groupers have recovered inside the Port-Cros MPA (Harmelin 2007). Other studies (Francour et al. 2001) concluded there was an increase in density of the top predators ('noble' fish species only) and a decrease in their prey in the Port-Cros MPA from 1980 to 2000, confirming the so-called 'reserve effect' (Francour 1997, 2007).

At the ecosystem scale, our study allows us to conclude that the Port-Cros MPA had positive effects on biomass recovery and to confirm the very low current fishing impact on the whole ecosystem inside the reserve. As expected, biomass is close to the unfished level, and functional biodiversity, as measured by the mean trophic level (Pauly \& Watson 2005), is conserved. Changes in food web structure have been shown to be important in fished areas compared to protected areas (Libralato et al. 2010), as revealed by a series of ecosystem indicators, including trophic spectra and transfer efficiencies between trophic levels.
Also, the present study confirms the efficiency of protection measures for dusky grouper, as the estimated annual rate of biomass accumulation reached about $10 \%$ for the large ones. Like Port-Cros, many other semi-protected areas in the north-western Mediterranean Sea have demonstrated the limited impact of small-scale professional fishing, which is an activity compatible with their conservation objectives (Francour et al. 2001). Thus, in spite of uncertainty in the outputs from the EcoTroph simulations due to the lack of baseline data, our scenarios seem to be consistent.

The assessment of the reserve effect could be improved by gathering more information on fishing effort. First, fishing scenarios should be based on catch data collected outside the reserve, where the extractions are less restricted, so that we could have a better estimate of a realistic higher fishing effort. Moreover, recreational fishing, even restricted and assumed very low, should be included in the fishing scenarios to give a complete view of the fishing effort currently applied, as this activity can potentially exert a large impact on marine ecosystems. In the Cape Creus MPA (Mediterranean Sea), for instance, the annual biomass extracted by spear fishing is equivalent to $40 \%$ of the annual biomass extracted by professional fishing, and spear fishing was confirmed as capable of inducing changes in the trophic structure of the fish community, by targeting the most vulnerable species (Lloret et al. 2008). Our fishing scenarios also confirm the potential impact of high fishing effort and high landings on the biomass of high trophic levels, corresponding to the species of interest. Unreported commercial catch is also known to be very high in the Mediterranean Sea (e.g. Coll et al. 2006).

\section{CONCLUSIONS}

Using a modeling approach, we conclude that the establishment of the Port-Cros reserve had positive effects on the biomass inside the MPA, but only local benefits outside the reserve. Our results also suggest that several field studies are needed to complement the existing body of knowledge. First, ecological studies about life cycles, migrations, and larval dispersal in relation to marine currents are necessary to assess the level of migrations inside and outside the Port-Cros MPA. For instance, data on fishing effort concentration and catch in the MPA surroundings could provide evidence of biomass export, as previously showed by Goñi et al. (2008) in 6 other MPAs in 
the Mediterranean Sea. Moreover, a monitoring system for all the species, including invertebrates and non-emblematic fish species, should be implemented long term for a better understanding of the dynamics of trophic interactions in the Port-Cros MPA. For a broader perspective, we could also consider carrying out comparative studies between equivalent Mediterranean MPAs, more or less exploited. We could also build interlocked Ecopath models, representing ecosystems at different scales: from a part of the coast to the entire Lion Gulf. Finally, the future expansion of the Port-Cros National Park, with the project of establishment of a peripheral zone, would be a good opportunity to implement better monitoring of all fishing activities (professional and non-professional) on a larger scale (inside and outside the MPA), notably by a closer cooperation between all the stakeholders (fishermen, managers, and scientists).

Focusing on trophic aspects and using ecosystem models such as Ecopath and EcoTroph appears to be a relevant approach to study the potential effects of MPAs. As snapshots of ecosystems, ecological models provide a consistent synthesis of current knowledge and highlight the indirect effects of protecting predator species, not only on their prey but also on the biomass of the whole ecosystem. Moreover, such an approach allows us to explore various ecological questions and to identify several important issues that deserve consideration in future studies of the effects of MPAs on marine resources and ecosystems.

Acknowledgements. We thank Marta Coll and 4 anonymous referees for useful comments on the manuscript. The present study was supported by the AMPHORE ('AMP et Optimisation des Ressources Halieutiques') project founded by the French ANR ('Agence Nationale de la Recherche'). Based on several case studies of locations in France and western Africa, this research project aims to assess the efficiency of MPAs to ensure the sustainable management of fishing resources. The authors acknowledge Aurélie Blanfuné from the Université de Nice Sophia-Antipolis, France, for providing the map of the Port-Cros MPA.

\section{LITERATURE CITED}

Abdulla A, Gomei M, Maison E, Piante C (2008) Status of marine protected areas in the Mediterranean Sea. IUCN and WWF, Malaga

- Afonso P, Fontes J, Santos RS (2011) Small marine reserves can offer long term protection to an endangered fish. Biol Conserv 144:2739-2744

> Albouy C, Mouillot D, Rocklin D, Culioli JM, Le Loch F (2010) Simulation of the combined effects of artisanal and recreational fisheries on a Mediterranean MPA ecosystem using a trophic model. Mar Ecol Prog Ser 412:207-221

Allen KR (1971) Relation between production and biomass. J Fish Res Board Can 28:1573-1581
Allison GW, Lubchenco J, Carr MH (1998) Marine reserves are necessary but not sufficient for marine conservation. Ecol Appl 8 (Suppl 1):79-92

Bell JD, Harmelin-Vivien L (1983) Fish fauna of French Mediterranean Posidonia oceanica seagrass meadows. 2. Feeding habits. Tethys 11:1-14

Belsher T, Houlgatte E, Boudouresque CF (2005) Cartographie de la prairie à Posidonia oceanica et des principaux faciès sédimentaires marins du Parc national de PortCros (Var, France, Méditerranée). Trav Sci Parc Nat PortCros 21:19-28

Bodilis P, Ganteaume A, Francour P (2003) Presence of 1 year-old dusky groupers along the French Mediterranean coast. J Fish Biol 62:242-246

Cadiou G, Bonhomme P (2006) Suivi de l'effort de pêche professionnelle dans les eaux du Parc national de PortCros. Année 2005. Rapport No. 05-006.83400 PC. GIS Posidonie, Marseille

Cadiou G, Boudouresque CF, Bonhomme P, Le Diréach L (2008) The management of artisanal fishing within the Marine Protected Area of the Port-Cros National Park (northwest Mediterranean Sea): A success story? ICES J Mar Sci 66:41-49

Chauvet C, Francour P (1989) Les mérous du parc national de Port-Cros: aspects socio-démographiques. Bull Soc Zool Fr 114:5-13

- Christensen V, Pauly D (1992) The ECOPATH II-a software for balancing steady-state ecosystem models and calculating network characteristics. Ecol Modell 61: 169-185

Christensen V, Walters C (2004) Ecopath with Ecosim: methods, capabilities and limitations. Ecol Modell 172: 109-139

Christensen V, Walters C, Pauly D (2005) Ecopath with Ecosim: a user's guide. November 2005 edn. Fisheries Centre, University of British Columbia, Vancouver, BC

Christensen V, Walters CJ, Pauly D, Forrest R (2008) Ecopath with Ecosim Version 6 user guide. Fisheries Centre, University of British Columbia, Vancouver, BC

Coll M, Palomera I, Tudela S, Sarda F (2006) Trophic flows, ecosystem structure and fishing impacts in the South Catalan Sea, northwestern Mediterranean. J Mar Syst 59:63-96

Coll M, Piroddi C, Steenbeek J, Kaschner K and others (2010) The biodiversity of the Mediterranean Sea: estimates, patterns, and threats. PloS ONE 5(8):e11842

Dufour F, Guidetti P, Francour P (2007) Comparaison des inventaires de poissons dans les aires marines protégées de Méditerranée: influence de la surface et de l'ancienneté. Cybium 31:19-31

Francour P (1990) Dynamique de l'écosystème à Posidonia oceanica dans le Parc National de Port-Cros. Analyse des compartiments matte, litière, faune vagile, échinodermes et poissons. Doctorat, Université Pierre et Marie Curie, Paris

- Francour P (1997) Fish assemblages of Posidonia oceanica beds at Port-Cros (France, NW Mediterranean): assessment of composition and long-term fluctuations by visual census. PSZNI: Mar Ecol 18:157-173

Francour P (2007) Evolution pluriannuelle de la faune ichtyologique des substrats rocheux et de l'herbier à Posidonia oceanica du Parc National de Port-Cros (Var, Méditerranée nord-occidentale): analyse de la période 1988-2006. Rapport No. PNPC 04022 83400. LEML, Universite de Nice, Nice 
Francour P, Harmelin JG, Pollard D, Sartoretto S (2001) A review of marine protected areas in the northwestern Mediterranean region: siting, usage, zonation and management. Aquat Conserv 11:155-188

Froese R, Pauly D (2009) FishBase. A global information system on fishes. Available at: www.fishbase.org (Version $11 / 2010)$

> Gascuel D (2005) The trophic-level based model: a theoretical approach of fishing effects on marine ecosystems. Ecol Modell 189:315-332

Gascuel D, Morissette L, Palomares MLD, Christensen V (2008) Trophic flow kinetics in marine ecosystems: toward a theoretical approach to ecosystem functioning. Ecol Modell 217:33-47

Gascuel D, Tremblay-Boyer L, Pauly D (2009) EcoTroph: a trophic-level based software for assessing the impact of fishing on aquatic ecosystems. Fisheries Centre Research Reports, Vol 1. Fisheries Centre, University of British Columbia, Vancouver, BC

> Gascuel D, Guénette S, Pauly D (2011) The trophic-level based ecosystem modelling approach: theoretical overview and practical uses. ICES J Mar Sci 68:1403-1416

> Goñi R, Adlerstein S, Alvarez-Berastegui D, Forcada A and others (2008) Spillover from six western Mediterranean marine protected areas: evidence from artisanal fisheries. Mar Ecol Prog Ser 366:159-174

Grüss A, Kaplan DM, Guénette S, Roberts CM, Botsford LW (2011) Consequences of adult and juvenile movement for marine protected areas. Biol Conserv 144:692-702

> Halpern BS, Warner RR (2002) Marine reserves have rapid and lasting effects. Ecol Lett 5:361-366

> Harmelin JG (1987) Structure et variabilité de l'ichtyofaune d'une zone rocheuse protégée en Méditerranée (Parc national de Port-Cros, France). PSZNI: Mar Ecol 8: 263-284

Harmelin JG (2007) Recensement de la population de mérou brun (Epinephelus marginatus: Pisces) du Parc national de Port-Cros (France, Méditerranée) en 2005 (collective paper under the supervision of J. G. Harmelin). Trav Sci Parc Nat Port-Cros 22:39-48

Hoenig J (1993) Empirical use of longevity data to estimate mortality rates. Fish Bull 81:898-903

Khoury C (1987) Ichtyofaune des herbiers de posidonies dans le Parc national de Port-Cros: composition, éthologie alimentaire et rôle dans le réseau trophique. Doctorat, Université de la Méditerranée, Marseille

Lester SE, Halpern BS, Grorud-Colvert K, Lubchenco J and others (2009) Biological effects within no-take marine reserves: a global synthesis. Mar Ecol Prog Ser 384: 33-46

Libralato S, Solidoro C (2010) Comparing methods for building trophic spectra of ecological data. ICES J Mar Sci 67 : 426-434

Libralato S, Christensen V, Pauly D (2006) A method for identifying keystone species in food web models. Ecol Modell 195:153-171

Libralato S, Coll M, Tempesta M, Santojanni A and others (2010) Food-web traits of protected and exploited areas

Editorial responsibility: Konstantinos Stergiou,

Thessaloniki, Greece of the Adriatic Sea. Biol Conserv 143:2182-2194

> Link JS (2010) Adding rigor to ecological network models by evaluating a set of pre-balance diagnostics: a plea for PREBAL. Ecol Modell 221:1580-1591

> Lloret J, Zaragoza N, Caballero D, Font T and others (2008) Spearfishing pressure on fish communities in rocky coastal habitats in a Mediterranean marine protected area. Fish Res 94:84-91

Mills LS, Soule ME, Doak DF (1993) The keystone-species concept in ecology and conservation. Bioscience 43: 219-224

> Mosquera I, Côté IM, Jennings S, Reynolds JD (2000) Conservation benefits of marine reserves for fish populations. Anim Conserv 3:321-332

Murawski SA, Wigley SE, Fogarty MJ, Rago PR and others (2005) Effort distribution and catch patterns adjacent to temperate MPAs. J Mar Sci 62:1150-1167

Opitz S (1996) Trophic interactions in Caribbean coral reefs. Technical Report 43. ICLARM, Manila

Palomares MLD, Pauly D (1998) Predicting food consumption of fish populations as functions of mortality, food type, morphometrics, temperature and salinity. Mar Fish Res 49:447-453

Pauly D (1980) On the interrelationships between natural mortality, growth parameters, and mean environmental temperature in 175 fish stocks. ICES J Mar Sci 39: 175-192

> Pauly D, Watson R (2005) Background and interpretation of the 'marine trophic index' as a measure of biodiversity. Philos Trans R Soc Lond B 360:415-423

Pinnegar JK (2000) Planktivorous fishes: links between the Mediterranean littoral and pelagic. Chapter 7: the ecological roles of planktivorous fishes in a Mediterranean rocky littoral system, evaluated using steady state modelling. $\mathrm{PhD}$ thesis in Marine Sciences and Coastal Management, University of Newcastle, Newcastle

Piraino S, Fanelli G, Boero F (2002) Variability of species' roles in marine communities: change of paradigms for conservation priorities. Mar Biol 140:1067-1074

> Power ME, Tilman D, Estes JA, Menge BA and others (1996) Challenges in the quest for keystones. Bioscience 46: 609-620

Ruitton S, Le Diréach L, Charbonnel E (2004) Evaluation du peuplement de poissons de l'épave «La Barge aux Congres» du Parc national de Port-Cros. Trav Sci Parc Nat Port-Cros 20:211-230

Sala E, Zabala M (1996) Fish predation and the structure of the sea urchin Paracentrotus lividus populations in the NW Mediterranean. Mar Ecol Prog Ser 140:71-81

> Stergiou KI, Karpouzi V (2002) Feeding habits and trophic levels of Mediterranean fish. Rev Fish Biol Fish 11: 217-254

> Sumaila UR, Guénette S, Alder J, Chuenpagdee R (2000) Addressing ecosystem effects of fishing using marine protected areas. ICES J Mar Sci 57:752-760

> Walters C, Christensen V, Pauly D (1997) Structuring dynamic models of exploited ecosystems from trophic mass-balance assessments. Rev Fish Biol Fish 7:139-172

Submitted: April 1, 2011; Accepted: March 3, 2012

Proofs received from author(s): May 17, 2012 